\title{
EXPERIMENTAL AND NUMERICAL FATIGUE ASSESSEMNT OF DUPLEX WELDED TRANSVERSAL STIFFENERS
}

\section{Burak KARABULUT ${ }^{\mathrm{a}, *}$, Geert LOMBAERT ${ }^{\mathrm{b}}$, Dimitri DEBRUYNE $^{\mathrm{c}}$, and Barbara ROSSI ${ }^{\mathrm{a}, \mathrm{d}}$}

${ }^{a}$ Department of Civil Engineering, KU Leuven, Belgium

Jan Pieter de Nayerlaan 5, Sint-Katelijne-Waver, Belgium.

Email: burak.karabulut@kuleuven.be

${ }^{\mathrm{b}}$ Department of Civil Engineering, KU Leuven, Leuven, Belgium

Email: geert.lombaert@kuleuven.be

${ }^{c}$ Department of Materials Engineering, KU Leuven, Gent, Belgium

Email: dimitri.debruyne@kuleuven.be

${ }^{\mathrm{d}}$ University of Oxford, Department of Engineering Science, Oxford, UK

Emails: barbara.rossi@new.ox.ac.uk

Keywords: Fatigue assessment; Hot spot stress method; Digital image correlation (DIC); Stainless steel; Transverse stiffeners.

Abstract. Fatigue is mostly the governing design criterion in girder steel bridges due to the presence of critical welded details. In this research, the hot spot stresses in welded cruciform duplex stainless steel joints are measured experimentally using digital image correlation as well as traditional strain ganges. They are also computed via FEM. The deduced fatigue lives are then compared to each other as well as to small-scale cyclic test results and to a series of literature data on similar welded details. The comparison highlights very consistent results and demonstrates applicability of the hot spot stress method to welded duplex details. 
The term "fatigue" was introduced in the 1850s when August Wöhler discovered railroad axles failing at stresses far below the material's static strength as a result of repetitive loading. However, fatigue verification [1] has always been a complex topic due to the intrinsic form of failure involving crack initiation through micro-cracks, crack propagation, finally followed by global failure. Research in the $20^{\text {th }}$ and the $21^{\text {st }}$ century mainly focused on understanding the failure mechanisms and providing design rules. Starting from the 1840s until the 1990s however, real fatigue problems occurring in structures were compiled and carefully studied, as in $[2,3,80]$. Fatigue was identified as one of the most important design criteria for orthotropic deck and girder steel bridges, especially when they include welded details [3]. Major institutions such as the American Society of Civil Engineers (ASCE) and Batelle Columbus Laboratories together with the National Bureau of Standards (NIST) describe, in [4-6], how often fatigue failures in metallic structures were encountered in the past.

It is around the 1960s that the effect of a high number of loading cycles on structural components of steel bridges and towers was extensively studied experimentally, leading to the implementation of the first fatigue check in the ECCS recommendations for steel bridges [7]. Later on, the European standard EN 1993-1-9 [8] was published, providing fatigue design and verification rules, applicable to all grades of structural steels, stainless steels and unprotected weathering steels, if these materials comply with the toughness requirements of EN 1993-1-10 [9]. For steel and composite structures, it is worth pointing two pivotal documents $[7,10]$ providing rules and methods to design steel structures submitted to fatigue.

\subsection{Fatigue prone details in steel bridges}

Bridges are submitted to, amongst other loads, time-variant actions such as traffic loads. In metallic bridges, fatigue is most of the time the governing limit state due to the presence of critical welded details, where stress concentrations, residual stresses as well as defects are present. As previously mentioned, general rules for the design of steel and composite structures against fatigue are provided in [7,10]. For critical welded details, a comparison of existing fatigue verification procedures is provided in [11]. In addition, several studies of critical fatigue details in bridges based on investigations of real damage cases have been reported in [12-14]. Fig. 1 gives an overview of the most common fatigue-prone details in steel bridges, according to [14] and shows that about $75 \%$ of all the details included in the chart may be welded ones. Since welding introduces geometrical discontinuities, hence stress concentrations, residual stresses as well as, in some cases, defects such as inclusions of mismatch, these locations are more susceptible to fatigue crack initiation and propagation. 


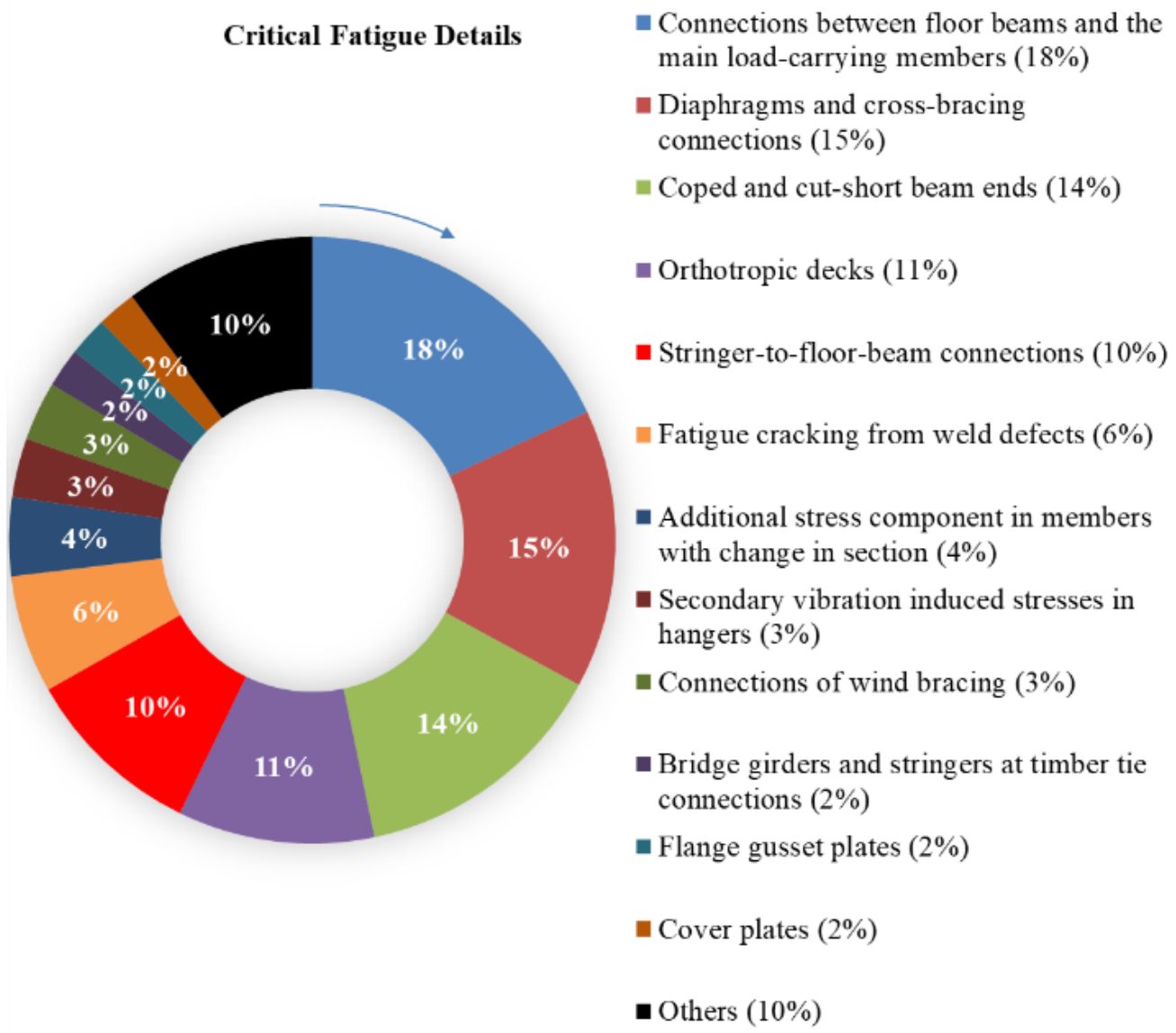

Fig. 1 Hierarchy of fatigue prone details.

\subsection{Duplex stainless steel in bridges}

Stainless steel, a Chromium based alloy, has recently been a popular construction material thanks to the combination of excellent corrosion resistance and good mechanical strength. Especially, duplex grades, with a balanced austenitic-ferritic microstructure, show higher proof strength and ductility than that of conventional austenitic grades. Over the last decade, those grades were relatively often used in bridges in corrosive environments [15]. The raised interest in stainless steels is also because of the recent studies demonstrating their excellent fatigue resistance. The EN 1.4162 and EN 1.4062 duplex grades are characterized by a lower Nickel and Molybdenum content (which is why they are called "lean") resulting in a more stable cost, but, at the same time, these grades are more prone to pitting corrosion. The ferritic-austenitic structure is sustained by providing Nitrogen and Manganese as an offset for lowered Nickel content, which maintains the balanced microstructure providing more economic solutions [16]. In mildly corrosive environments (Corrosion Resistance Class III according to [17]), they may offer a good alternative to coated carbon steel or to more traditional austenitic grades (regarding the initial material cost). Some studies [18-21] indeed prove that those grades have a similar or higher corrosion resistance as austenitic stainless steel grades EN 1.4307 and EN 1.4404. These duplex grades are also identified by good weldability using similar welding 
processes to the ones used for other conventional grades, demonstrating why they are increasingly used in welded constructions in mildly corrosive environments [15,22].

Although several established structural design codes for stainless steel exist, such as EN 1993-1-4 [23], studies have highlighted undue conservatism in some of their provisions, leading to inefficient use of the materials in structures. Additional literature review [24-26] reveals few but relevant information about the fracture toughness and the fatigue behaviour of stainless steels, in which, overall, mostly austenitic grades were studied. Very little research was however performed on lean duplex grades, although these grades are currently used in structures exposed to cyclic loads [15,22]. Moreover, the fatigue strength curves and the categorization of structural details present in Eurocode 3 Part 1-9 are mainly based on tests carried out on carbon steel details with a nominal yield strength $\mathrm{f}_{\mathrm{y}}$ ranging between 235 and $400 \mathrm{MPa}$ (S235 and S355 are mostly studied). Several studies however point out the higher fatigue life associated with higher strength materials, such as duplex stainless steel grades [25,27]. For example, in the Research for Coal and Steel (RFCS) project Bridgeplex [27], the technical feasibility of welded bridge construction made of duplex grade EN 1.4462 is studied. A series of experimental tests is performed on welded joints, showing a higher fatigue life in comparison with carbon steel equivalents. However, it is not possible at the moment to fully exploit the higher materials' strength because the design is based on structural details, regardless of the performance of the base materials.

In this article, the fatigue performance of welded duplex details is studied. To start with, the hot spot stress (HSS) method, which is very widely used as a fatigue verification approach, is elaborated from a general perspective. The method is then used to assess the fatigue life of welded duplex stiffeners based on experimental measurements. For the measurements carried out in the present research, strain gauges and contactless digital image correlation method (DIC) were used. In addition, the HSS is also numerically evaluated and compared to the measurements. Last, the obtained fatigue strength (S-N) curves based on the HSS method are compared to the nominal detail category as per EC 1993-1-9 as well as to fatigue lives found in the literature for similar details, especially considering steel grades with $\mathrm{f}_{\mathrm{y}}$ greater than $400 \mathrm{MPa}$.

\subsection{Fatigue failure mechanisms and fatigue verification}

The fatigue failure mechanism is composed of three distinct phases: crack initiation, crack propagation and, finally, global failure. The crack initiation phase is described as initiation of microscopic shear cracks from the surface of a structural component on crystallographic slip planes as intrusions and extrusions [3]. The first phase described hereof is usually not sufficient to result in ultimate failure. The second phase involves growth of the micro-cracks to macro-scale following the previously initiated local plastic deformations. The cracks propagate following a direction perpendicular to the applied loading plane. These two phases result in global failure of the structural components when the cracks become too large to maintain stability. The metallic structures subjected to high-cycle fatigue regime (fatigue life $-\mathrm{N}>10^{4}$ cycles) spend most 
of their fatigue life in the crack initiation stage. On the contrary, the crack propagation stage constitutes most of the fatigue life of a metallic component subjected to low cycle fatigue $\left(\mathrm{N}<10^{4}\right.$ cycle). Based on the theories and extensive investigations about fatigue failure mechanisms, fatigue verification methods are proposed such as nominal stress approach, hot spot stress approach, notch stress approach, fracture mechanics, etc.

\section{THE HOT SPOT STRESS METHOD}

According to [3], the hot spot stress method is based on theories of crack initiation, in cases where the fatigue cracks initiate through local stress concentrations on the surface of welded details due to geometric discontinuities (e.g. weld toe of a fillet welded detail). Fatigue analysis techniques are categorized in: stress life method (nominal stress method, HSS method and effective notch stress approach); fracture mechanics; strain life method and field measurement data [3]. Fatigue is a linear elastic problem with materials experiencing failure at stress levels far below the materials' static strength. The stress life method uses the S-N curve approach i.e. based on a relationship (most of the time a linear or multilinear relationship known as the Wöhler curve) between applied stress range and fatigue life [28]. Quite a lot of research focussed on improving the relationship between the applied stress range and the fatigue life, such as [29-31]. All of these studies led to an increasing interest in the nominal stress approach which became one of the most popular fatigue design methods used in engineering applications. The popularity of the method comes from its simplicity (it is based on the linear elastic structural mechanics theory). The nominal stress approach considers the global stresses of a macro detail and neglects the local stress concentration effects. The global stresses are those calculated far enough from the stress concentration zone so that a uniform stress distribution is reached. Depending on the geometry of the detail, either hand calculation or numerical analysis for more complex geometries can be used to determine the nominal stress. The approach has the following drawbacks: (i) it is not applicable when the studied detail geometry is so complex that it is difficult to assign a detail category; (ii) it is unable to represent complex loading conditions and, (iii) it is not possible to capture size effect of dimensional differences [32,33]. This led to an increasing interest in fatigue verification methods based on the local stress concept, HSS method being the most commonly adopted one [34]. The first investigations were made in the 1960s where fatigue strength was related to measured local stress adjacent to the weld toe $[35,36]$. The HSS method is used where stress-raising effects due to geometrical discontinuities exist (e.g. welded girder or orthotropic deck bridges). The so-called HSS is the nominal stress amplified by a stress concentration factor. The latter is calculated based on extrapolation of surface stresses at neighbouring points adjacent to the weld toe where the initiation of fatigue cracks is expected to occur. The HSS can be obtained both by experimental measurements or numerical simulations which is what will be presented in that research. The possibility to compute the HSS with finite element models (FEM) makes the method even more attractive since it gives the analyst control over many parameters such as certain locations, directions, complex loading scenarios or extraction of stress paths. It is of common 
interest among researchers to have more coarsely meshed model to understand the global structural behaviour and, then, to build sub-models (the studied detail) with denser meshes. Refining the mesh enables the analyst to read out stresses at the very location of the extrapolation points. The computed HSS is evidently influenced by the geometry of the local weld shape as well as by the mesh density satisfying the model convergence [37]. Therefore, many studies focussed on the influence of the model parameters on the computed HSS such as the element type, mesh type or mesh size [34,38-42]. It was mostly concluded that a compromise should be found without jeopardising the accuracy (ensuring converged results) of the model or unnecessarily increasing the computational time. Most of the examples in the literature until the 1970s mainly focussed on the empirical derivation of stress concentration factors for tubular joints [43-48], until Yagi et. al. [49] proposed an extrapolation strategy for plated elements after the 1980s. Some researchers also proposed and applied through thickness linearization methods in addition to surface extrapolation techniques [32,50-52]. Many others investigated the efficiency of the HSS method through comparative studies [33,51-56]. It was concluded from most of these studies that the HSS method is an accurate tool for fatigue verification $[34,51,54]$. All of these investigations led to an increasing interest in the method and it was widely accepted as an efficient fatigue verification tool by many national and international standardisation bodies [7,8,57,58]. EN 1993-1-9 only briefly refers to the method but does not provide any guidance. Therefore, one might refer to the guidelines of the International Institute of Welding (IIW) which give detailed information on how to determine and extrapolate the HSS both experimentally and numerically [59-60].

\subsection{Assessing the hot spot stress}

The HSS method allows the analyst to obtain the stress either numerically through FE analysis or experimentally. In any case, stress extrapolation is performed via the use of linear or quadratic functions given in Eqs. 1-2 for type a hot spot (Fig. 2).

\section{Linear extrapolation:}

Quadratic extrapolation:

$$
\begin{gathered}
\sigma_{H S}=1.67 \sigma_{0.4 t}-0.67 \sigma_{1.0 t} \\
\sigma_{H S}=2.52 \sigma_{0.4 t}-2.24 \sigma_{0.9 t}+0.72 \sigma_{1.4 t}
\end{gathered}
$$

The extrapolation functions ensure the elimination of stress singularities by excluding the stress raising effects of the weld profile while including the ones of the structural discontinuities [60-62]. This is the reason why traditional fatigue design techniques relying on the nominal stress approach are not as effective as the HSS method for complex geometries [34]. The nonlinear extrapolation is generally recommended instead of linear extrapolation in cases where nonlinear structural stress increase is present in front of the welded joint with various gradients and nonlinearities $[10,48]$. When the HSS is experimentally measured, the IIW guideline recommends using traditional approaches (conventional strain gauges for example). Yet recent years have experienced an increasing interest in optical contactless measurement techniques such as 
Digital Image Correlation (DIC) [63]. Research so far mostly focused on the applicability of this technique to carbon steel or aluminium details. Presently, the investigations are made on a welded duplex stainless steel detail.

It is worth noting that welding duplex grades requires specific attention to maintain the balanced microstructure, essential to corrosion resistance. This results in: (i) lower heat input; (ii) narrowed heat affected zone (HAZ); and, (iii) different residual stress distribution and geometrical imperfections compared to carbon steel equivalents.

\subsubsection{Strain gauges}

When the HSS is measured experimentally with strain gauges, their placement is based on experimental investigations of critical fatigue details present in orthotropic bridge decks $[41,43-46,64]$. The placement and number of strain gauges depend on the extent of shell bending stresses, on the wall thickness and on the type of structural stress. According to [7,10], the centre point of the first gauge, whose gauge length should not exceed $0.2 \mathrm{t}$, is located at a distance of $0.4 \mathrm{t}$ from the weld toe. If this is not feasible in practice, for example due to a too small plate thickness, the leading edge of the gauge should be placed at a distance of $0.3 \mathrm{t}$ from the weld toe. The extrapolation procedure and recommended number of gauges are as depicted in Fig. 2.

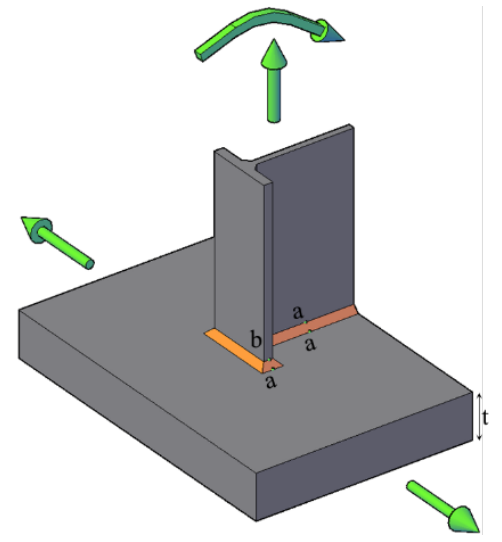

(a)

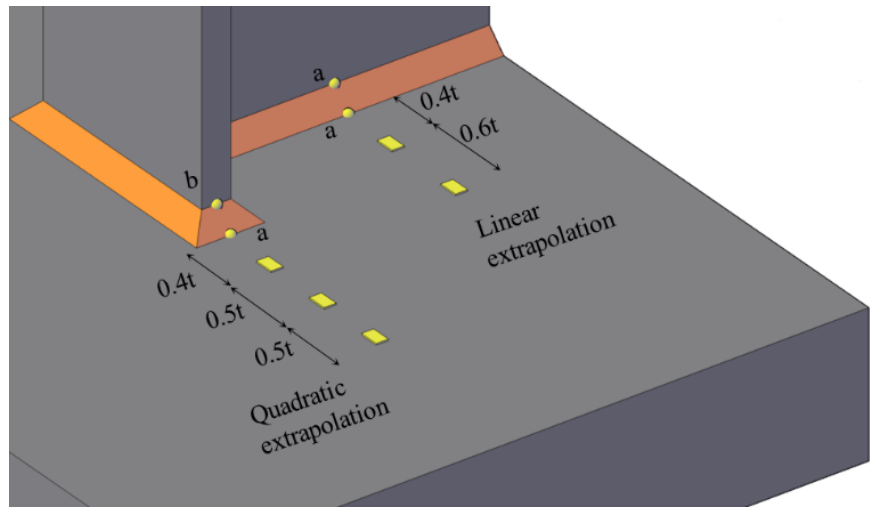

(b)

Type a $\Rightarrow$ weld toe at plate surface Type $b \Rightarrow$ weld toe at plate edge

Fig. 2 General scheme of: (a) type of hot spots and extrapolation paths; (b) extrapolation paths and placement of strain gauges.

\subsubsection{Digital image correlation (DIC)}

Using the DIC technique, multiple digital cameras take images of a random pattern speckled onto the tested specimen. An image processing software correlates the deformed shape of each speckle to the un-deformed one for derivation of the entire strain field [63]. This technique was at first exclusively used in material sciences, but lately is also becoming popular in structural engineering $[65,66]$. Presently, the processing of the measured data is performed using the virtual fields method 

findings were underlined in [79].

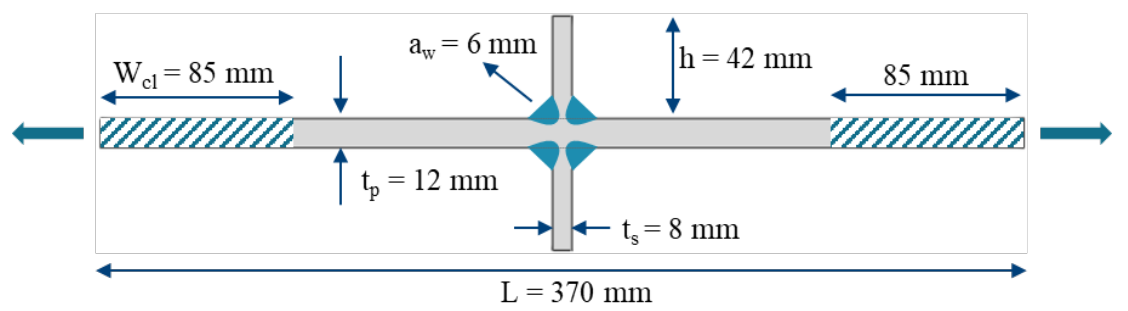

(a)

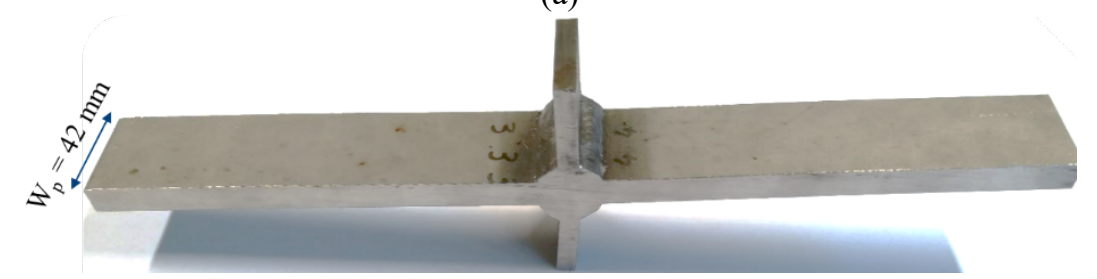

(b)

Fig. 3 Geometry of the studied transversal stiffener.

\subsection{Material characterization}

Static tensile tests were carried out on dog-bone coupons in order to characterize the mechanical properties of both 12 $\mathrm{mm}$ (base plate) plates and $8 \mathrm{~mm}$ (stiffeners). The measurements were performed via DIC. Tests were performed in both 

transverse direction (TD) and rolling direction (RD) and repeated 3 times. The dimensions of the tested specimens together with the test results can be seen in Fig. 4. The results of the tensile coupon test of the $12 \mathrm{~mm}$ base plate are provided Fig. 4c.

3 For each specimen, Young's modulus E is calculated as the slope of the stress-strain relationship between 10\% and $40 \%$ of

4 the yield strength defined as the proof strength at a plastic strain level of 0.2\% in DMSSS 2017 ([17]).

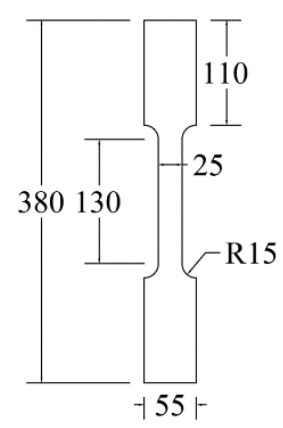

(a)

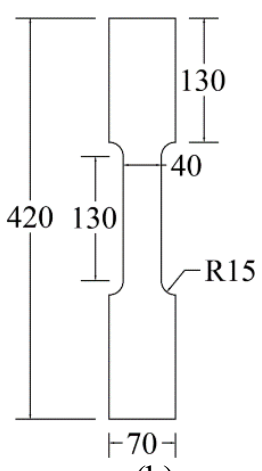

(b)

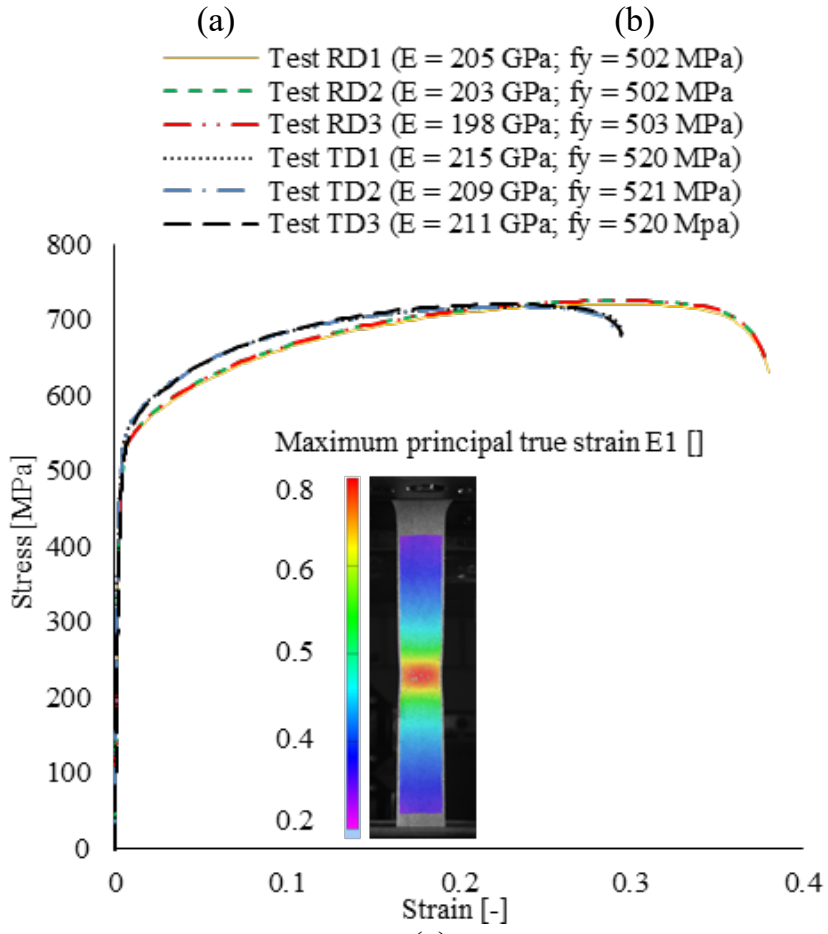

(c)

Fig. 4. Tensile test results: (a) coupon geometry for $12 \mathrm{~mm}$; (b) coupon geometry for $8 \mathrm{~mm}$; (c) test results - engineering stress vs. strain.

\subsection{Welded sample preparation and characterization}

The gas metal arc welding (GMAW) process was used to manufacture fillet welds of a cruciform joint, over a wide plate of $500 \mathrm{~mm}$ by $400 \mathrm{~mm}$. The rolling direction of the plates corresponds to the loading direction since it always shows the least resistance. The cutting of the welded test specimens was performed via Wire Electrical Discharge Machining (Wire EDM) Cutting technology, see Fig. 5. 


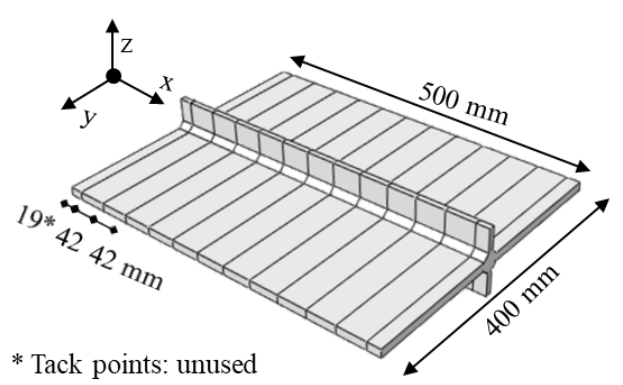

Fig. 5. Wire EDM cutting of the test pieces.

Welding stainless steel requires special attention with additional cautionary steps to be taken when compared to welding mild carbon steel. For duplex stainless steels, maintaining the balanced phases of the microstructure made of ferrite and austenite is crucial since this is ensuring ductility and corrosion resistance of the weld. The balanced microstructure is essentially maintained by limiting the heat input and respecting the inter-pass temperature. Keeping the heat input between $0.5-1.5 \mathrm{~kJ} / \mathrm{mm}$ and inter-pass temperature of $150^{\circ} \mathrm{C}[70]$, one not only limits the excessive formation of ferrite content in the HAZ, but also hinders the risk of forming intermetallic phases, which both induce brittle behaviour and have adverse effects on corrosion resistance. Besides, the selection of the right filler material is also of high importance to compensate element loss, avoid segregation and prevent excessive ferrite formation in the weld metal (WM) and HAZ. The filler material has to overmatch the base material both mechanically and chemically. Presently, the chosen filler material was Böhler CN 24/9 LDX with $1.0 \mathrm{~mm}$ solid wire. The welding was performed semi-automatically in the Welding Center of KU Leuven on Technology Campus De Nayer. Pulse-arc welding method was used ensuring satisfactory penetration without excessive heat input. The current and voltage were measured by means of Dewetron software during welding and the measured welding parameters were as follows: voltage $10 \mathrm{~V}$; current $198 \mathrm{~A}$; wire speed $10.6 \mathrm{~m} / \mathrm{min}$, travel speed $3.90 \mathrm{~mm} / \mathrm{s}$; pulse time $2.1 \mathrm{~ms}$; pulse frequency $160 \mathrm{~Hz}$; heat input $1.2 \mathrm{~kJ} / \mathrm{mm}$.

The preliminary test pieces were visually inspected for inadequate or excessive penetration, mismatch, undercut, surface cracks or inclusions. According to EN ISO 5817 [71], the quality level was determined as B, which refers to the highest quality. The welded pieces underwent destructive tests for the microstructural investigation by being cut, polished and etched. Lichtenegger and Bloech colour etching (LBI) gave a good contrast between different phases of ferrite and austenite. The balance between these phases was microscopically checked with a Hirox KH-8700 digital optical microscope, 30 images per base metal (BM), HAZ and fusion zone (FZ) were taken for further processing with ImageJ software which is based on pixel counting following the different contrast between black and white according to ASTM E 562 [72]. The ferrite content was compared to the recommendations given in [73] and the balance of the microstructure was found to be very satisfactory (see Table 1). In Fig. 6, one can see the distribution of ferritic and austenitic phases. Ferrite and austenite can be seen in dark and white contours respectively. The length of the HAZ was measured multiple times in the microscopic scale and the average 
HAZ is 20 to 40 times larger.

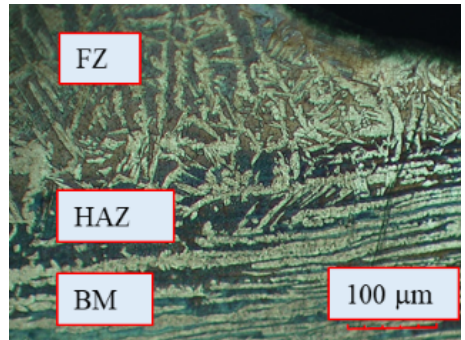

(a)

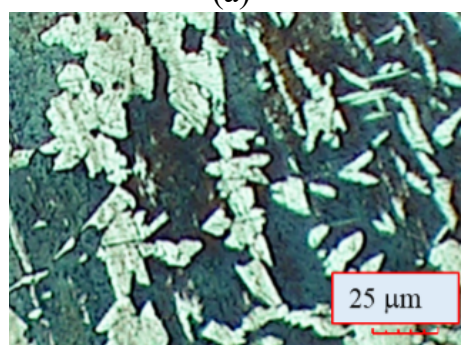

(c)

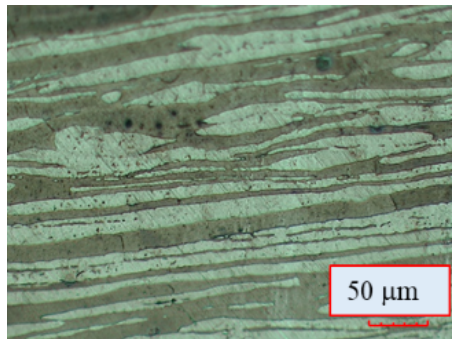

(b)

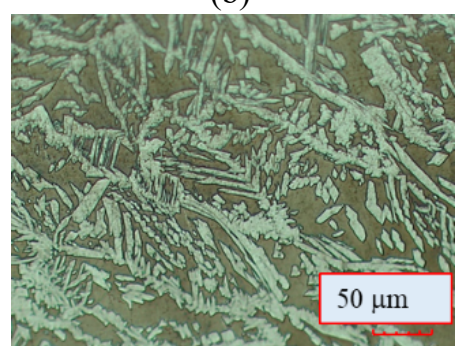

(d)
Fig. 6. Microstructure of EN 1.4162 specimen: (a) general view; (b) BM; (c) HAZ - $0.08 \mathrm{~mm}$; (d) fusion zone (FZ).

Table 1. Ferrite content measurement of the EN 1.4162 specimen.

\begin{tabular}{cccc}
\hline Welding zone & Ferrite content average [\%] & Standard deviation [2 $\sigma]$ & Suggested ferrite content [\%] \\
\hline B.M & 54 & $54 \pm 7$ & 40 to 60 \\
HAZ & 66 & $66 \pm 8$ & 25 to 75 \\
FZ & 53.6 & $53.6 \pm 8$ & 25 to 60 \\
\hline
\end{tabular}

\subsection{Global geometrical imperfections}

The IIW guideline refers to the fatigue strength modification due to misalignment based on an effective magnification factor $\mathrm{km}$ considering the presence of secondary shell bending stresses. A certain degree of misalignment is already covered in the S-N curves $\left(\mathrm{km}_{\mathrm{m}}=1.05\right)$. In the case of measured geometric imperfections, the factor needs to be recalculated according to Fig. 8(c) and equations (3-5). In case no measurement of misalignment is available, a default value $\mathrm{km}=1.10$ is recommended $[7,10]$. For the present welded specimen, the initial geometry was measured by taking several static images on both sides of the specimen and computing its geometry through DIC (Fig. 7 and Fig. 8).

Based on Fig. 8, the calculated misalignment factor $\mathrm{k}_{\mathrm{m} \text {,calculated }}$ is equal to 1.06 . It implies that the numerically computed HSS, which will not include geometrical imperfections, needs to be amplified by $1.06 / 1.05=1.01$. This value also means that the effect of misalignment is negligible for the present test specimen. This is due to the fact that the sample was continuously clamped during welding and remained constrained until the cooling down phase. 


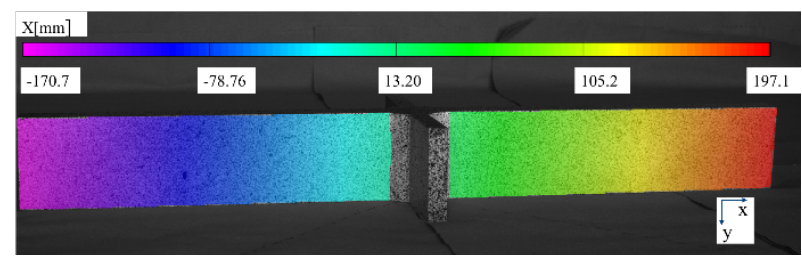

(a)

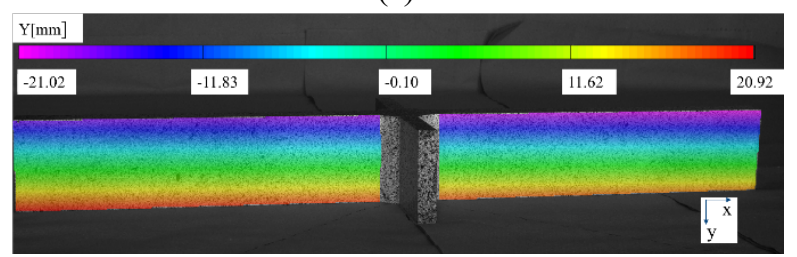

(b)

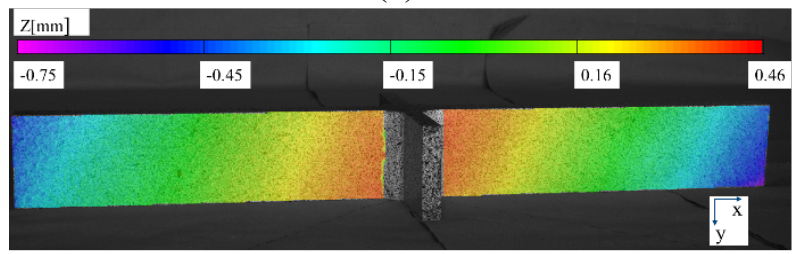

(c)

1 Fig. 7 Geometric imperfections of the front view: (a) horizontal axis straightness; (b) vertical axis straightness; (c) out of plane straightness of the front view.

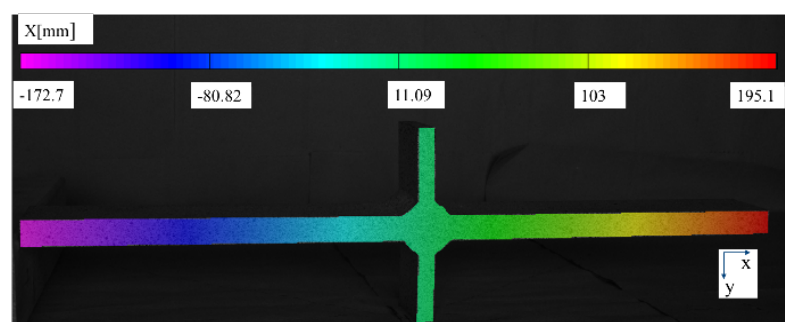

(a)

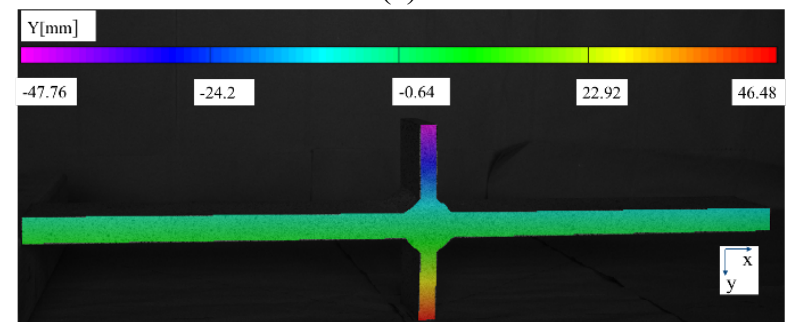

(b)
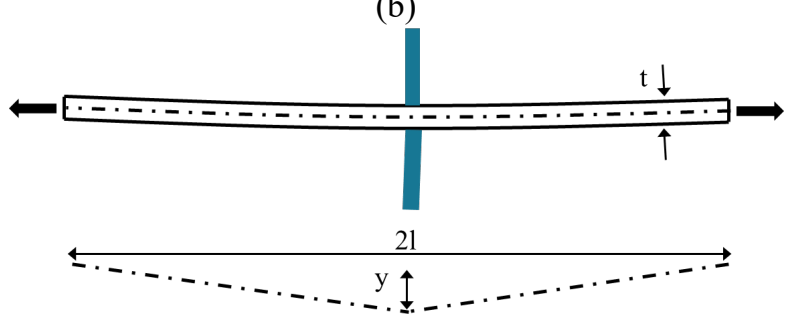

(c)

3 Fig. 8 Geometric imperfections of the side view: (a) horizontal axis straightness; (b) vertical axis straightness; (c) needed 4 parameters for the formulation of $\mathrm{km}$.

$$
k_{m, e f f}=\frac{k_{m, \text { calculated }}}{k_{m, \text { already covered }}}
$$

$$
k_{m, \text { calculated }}=1+\frac{3 * y}{t} \cdot \frac{\tanh (\beta / 2)}{\beta / 2}
$$




$$
\beta=1+\frac{2 . l}{t} \cdot \sqrt{\frac{3 \cdot \sigma_{m}}{E}}
$$

where $\sigma_{\mathrm{m}}$ is the membrane stress, here $80 \mathrm{MPa}$, i.e. the nominal stress of the detail category.

\subsection{Measurement of hot spot stress with DIC and strain gauges}

The hot spot stress was determined using both the traditional measurement method with conventionally bonded strain gauges and the optical measurement technique with DIC. A static tensile test was performed on the welded specimen by means of an Instron 1500 HDX series tensile-compression bench. A displacement-controlled testing procedure was used, following the recommendations of EN ISO 6892-1 [74] with a strain rate of $0.00025 \mathrm{~s}^{-1}$.

Firstly, DIC was used during the test to capture the full strain field, computed through MatchID, on one side of the sample, see Fig. 9. The speckle pattern was applied by diffusion in air of black paint onto a previously painted uniform white surface, which can be seen in Fig. 9(b). The minimum speckle dimensions were 0.1 by $0.1 \mathrm{~mm}$. The cameras used were of the type Manta G-895 with 8.95 Megapixel resolution and positioned at $300 \mathrm{~mm}$ distance from the sample. The strain field near the weld bead can be seen in Fig. 9(c). The applied load corresponds to $43 \mathrm{kN}$ leading to a uniform stress distribution of $80 \mathrm{MPa}$, i.e. the nominal stress range of the detail category, away from the weld toe. The selected parameters for the DIC computations are provided in Table 2. These parameters are obtained from a performance analysis which is based on a relationship between principal stress and VSG size. The parameters are selected where the principal stress component becomes insensitive to VSG size yet not exceeding the recommended physical strain gauge size which is maximum $0.4 \mathrm{t}$ according to the IIW guideline. This is done to acquire a smooth principal stress pattern without losing the accuracy due to loss of the signal. As can be seen in Fig. 9(c), principal stress strips alongside the weld line in $x$ direction were evaluated, with increments of $0.15 \mathrm{~mm}$ (6 pixels) along the vertical y axis which basically correspond to the step size (the conversion factor from $\mathrm{mm}$ to pixels for the current setup is 40 ). Along each of these strips, the average of the principal stresses was calculated excluding half of the subset away from the edge of the region of interest (ROI). This is done to avoid extreme value points due to distortion of the image close to the specimen edges. In order to have a direct comparison with strain gauges, stress readouts were also done at the very locations where the strain gauges were attached i.e. at $0.4 \mathrm{t}$ and $1.0 \mathrm{t}$, see Fig. $9(\mathrm{~d})$.

Table 2. Optimized DIC parameters after performance analysis.

\begin{tabular}{ccccc}
\hline Measurement type* $^{*}$ & VSG (px) & Subset size (px) & Step size (px) & Strain window (px) \\
\hline Experiment/Imperfection & 213 & 21 & 6 & 33 \\
\hline
\end{tabular}




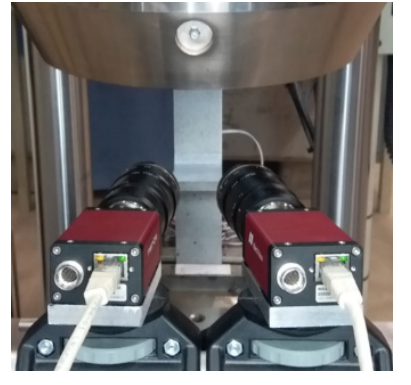

(a)

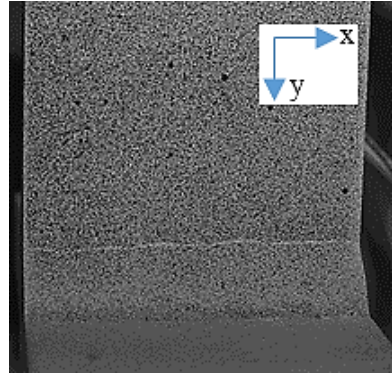

(b)

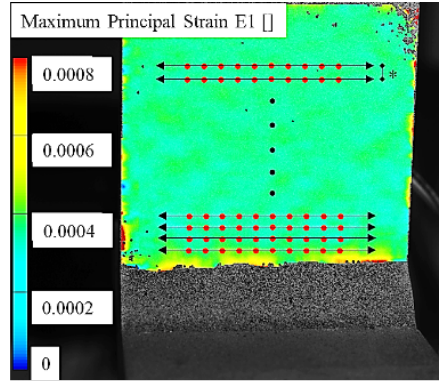

* $0.15 \mathrm{~mm}$

(c)

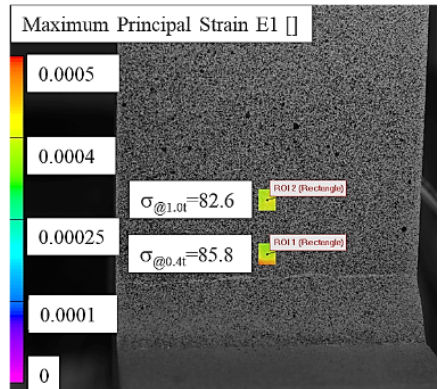

(d)

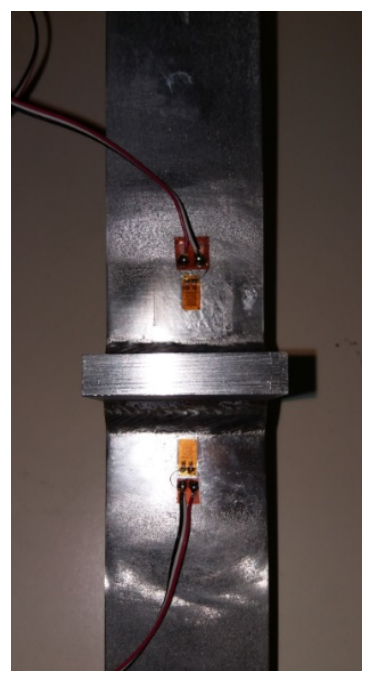

(a)

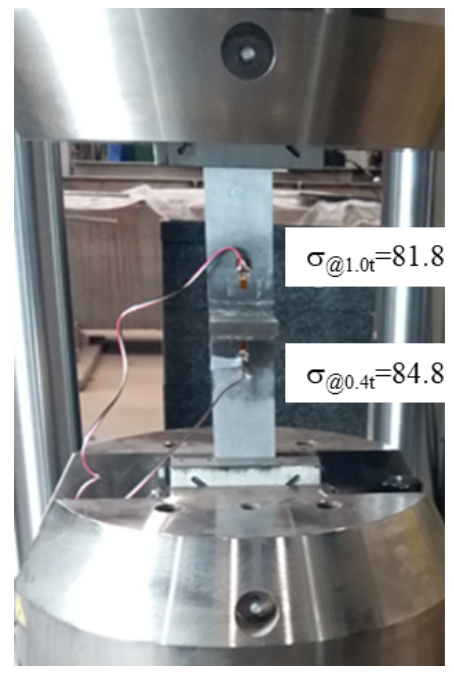

(b)

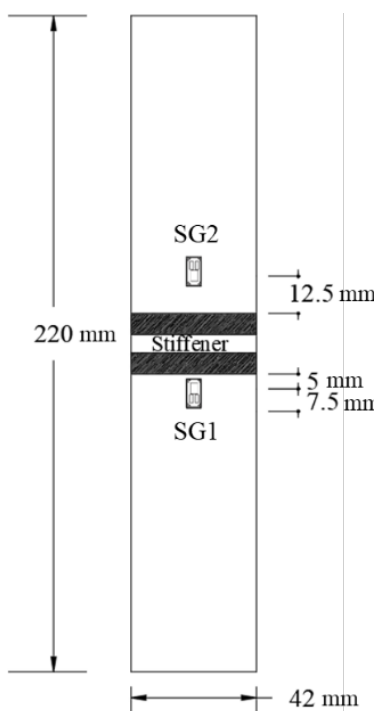

(c)

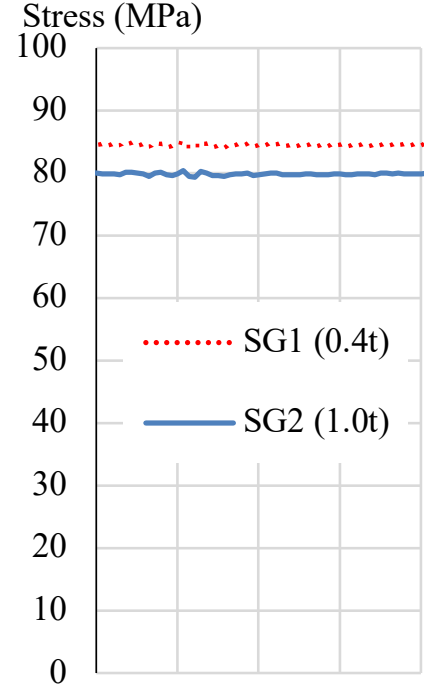

(d)

Fig. 10. Test with strain gauges: (a) bonded strain gauge; (b) test setup - stresses are in MPa; (c) placement scheme of strain gauges; (d) stress readout.

\subsection{Comparison of results}

The results of the DIC and the strain gauges are compared in Fig. 11 where the average principal stress distribution was taken according to the methodology discussed in the previous paragraph and illustrated in Fig. 9(c). Both stress values show great agreement with each other. The HSS measured via strain gauges is $87.6 \mathrm{MPa}$ whereas it equals $87.9 \mathrm{MPa}$ using DIC, which will lead to a similar predicted fatigue life as will be explained later. It must be noted that the first principal stress is perpendicular to the weld line since loading misalignment was avoided and verified through the uniformity of the strain field. 


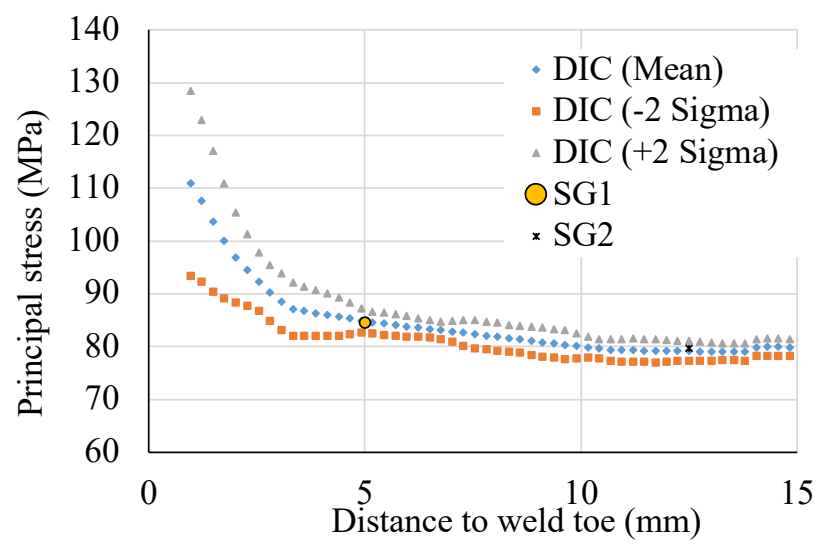

Fig. 11. Comparison of results (DIC vs. strain gauges).

2

3

\section{NUMERICAL COMPUTATION OF THE HSS}

The design of the test specimen was performed via FE analyses using Abaqus/Standard. In the reference model, the boundary conditions (BCs) were chosen such that the specimen is subjected to uniform tension, resulting in a nominal stress range in the flange corresponding to the detail category FAT 80. The reference model was built with the optimal parameters recommended in $[7,10]$. It is composed of 8-noded linear solid elements with reduced integration, the element size was limited to $0.4 \mathrm{t}$ and a linear elastic material behaviour was used $(\mathrm{E}=200 \mathrm{GPa}$ for $\mathrm{EN} 1.4162)$. Linear extrapolation was then used to compute the HSS at the weld toe. The stress field obtained from the FEM together with the calculation scheme of the HSS can be seen in Fig. 12.

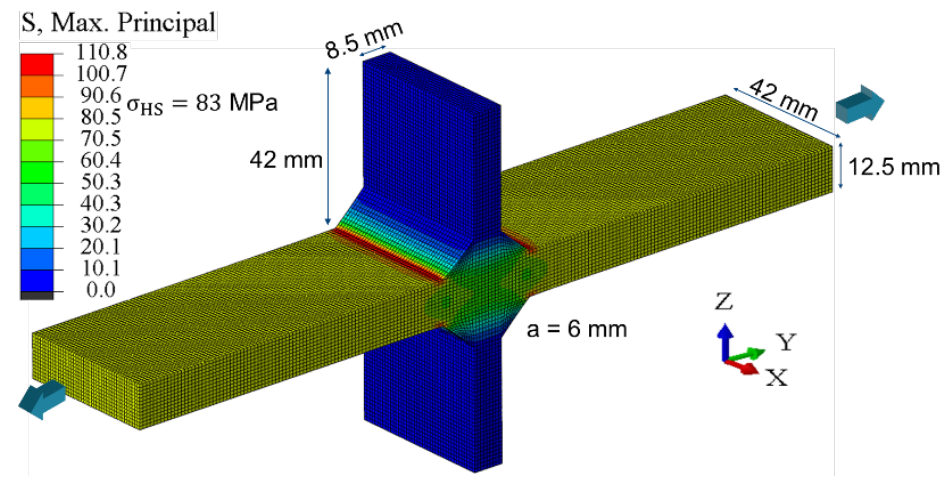

(a)

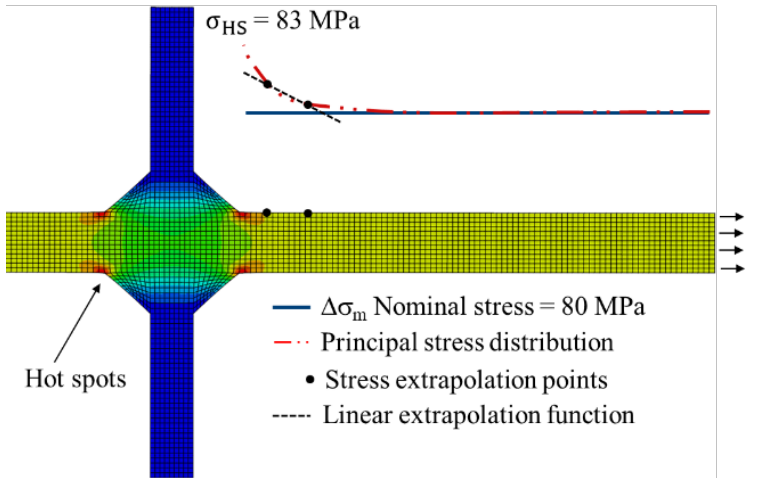

(b)

Fig. 12. FEM of the test piece: (a) principal stress results; (b) calculation of the HSS.

A sensitivity analysis of the computed stress was performed considering the following model and geometrical parameters: mesh size (coarse vs. fine); element type (linear 8-node vs. quadratic 20-node); shell versus solid finite element; integration method (reduced versus full); detail length $(\mathrm{L}=100 \mathrm{~mm}, 200 \mathrm{~mm}$ and $600 \mathrm{~mm}$ ); extrapolation method for the HSS (linear versus quadratic); joint type (T-joint and cruciform); fillet weld angle $\left(30^{\circ}, 45^{\circ}\right.$ and $\left.60^{\circ}\right)$; weld throat thickness $\left(\mathrm{a}_{\mathrm{w}}=3 \mathrm{~mm}\right.$ and $6 \mathrm{~mm})$; stiffener thickness $\left(\mathrm{t}_{\mathrm{s}}=6 \mathrm{~mm}, 8 \mathrm{~mm}\right.$ and $\left.10 \mathrm{~mm}\right)$; base plate thickness $\left(\mathrm{t}_{\mathrm{p}}=8 \mathrm{~mm}, 10 \mathrm{~mm}\right.$ and $\left.12 \mathrm{~mm}\right)$; base plate width $\left(\mathrm{W}_{\mathrm{p}}=21,42 \mathrm{~mm}\right.$ and $\left.63 \mathrm{~mm}\right)$. As an example, for the design against fatigue, the selection of the mesh size in the IIW 
1 guideline is limited to a coarse or fine mesh (element size relative to plate thickness $\leq 0.4 \mathrm{t}$ and $\leq 1.0 \mathrm{t}$ respectively). Herein,

2 three meshes, from coarse to very fine as shown in Fig. 13 (element size varying between $\leq 12.5 \mathrm{~mm}$ to $\leq 1 \mathrm{~mm}$ ), were

3 studied and the maximum relative difference among the assessed HSS was $5.5 \%$ as illustrated in Fig. 13 . $(\sigma \mathrm{hs}, 1 \mathrm{~mm}=82.2$

$\left.4 \mathrm{MPa}, \sigma_{\mathrm{hs}, 12.5 \mathrm{~mm}}=87.6 \mathrm{MPa}\right)$. Similar investigations were performed for the rest of the mentioned parameters and the results

5 are summarized in Table 3 and Table 4, showing very little influence on the magnitude of HSS. The sensitivity analysis

6 allowed us to check that the fixed test specimen dimensions, respecting the dimensional and mechanical restrictions of the

7 tensile and dynamic benches, would provide sensitive results. Table 3 . Sensitivity analysis of the computed HSS to the

8 geometrical parameters.

\begin{tabular}{|c|c|c|c|}
\hline \multicolumn{2}{|c|}{ Sensitivity analysis on geometrical parameters } & \multirow{2}{*}{$\begin{array}{c}\text { HSS } \\
84.09 \mathrm{MPa}\end{array}$} & \multirow{2}{*}{$\begin{array}{c}\text { Maximum variation } \\
0.3 \%\end{array}$} \\
\hline Joint type & T-joint & & \\
\hline & Cruciform & $83.88 \mathrm{MPa}$ & \\
\hline \multirow[t]{3}{*}{ Fillet weld angle } & $30^{\circ}$ & $84.50 \mathrm{MPa}$ & $0.5 \%$ \\
\hline & $45^{\circ}$ & $84.31 \mathrm{MPa}$ & \\
\hline & $60^{\circ}$ & $84.09 \mathrm{MPa}$ & \\
\hline \multirow[t]{2}{*}{ Weld throat thickness $\left(a_{w}\right)$} & $3 \mathrm{~mm}$ & $85.40 \mathrm{MPa}$ & $0.1 \%$ \\
\hline & $6 \mathrm{~mm}$ & $85.28 \mathrm{MPa}$ & \\
\hline \multirow[t]{3}{*}{ Stiffener thickness $\left(t_{s}\right)$} & $6 \mathrm{~mm}$ & $85.43 \mathrm{MPa}$ & $0.2 \%$ \\
\hline & $8 \mathrm{~mm}$ & $85.28 \mathrm{MPa}$ & \\
\hline & $10 \mathrm{~mm}$ & $85.48 \mathrm{MPa}$ & \\
\hline \multirow[t]{3}{*}{ Base plate thickness $\left(t_{p}\right)$} & $8 \mathrm{~mm}$ & $84.51 \mathrm{MPa}$ & $0.9 \%$ \\
\hline & $10 \mathrm{~mm}$ & $84.79 \mathrm{MPa}$ & \\
\hline & $12 \mathrm{~mm}$ & $85.28 \mathrm{MPa}$ & \\
\hline \multirow[t]{3}{*}{ Base plate width $\left(\mathrm{w}_{\mathrm{p}}\right)$} & $21 \mathrm{~mm}$ & $85.06 \mathrm{MPa}$ & $0.6 \%$ \\
\hline & $42 \mathrm{~mm}$ & 85.28 MPa & \\
\hline & $63 \mathrm{~mm}$ & $85.64 \mathrm{MPa}$ & \\
\hline \multirow[t]{3}{*}{ Detail length (L) } & $100 \mathrm{~mm}$ & $85.65 \mathrm{MPa}$ & $0.5 \%$ \\
\hline & $200 \mathrm{~mm}$ & $85.53 \mathrm{MPa}$ & \\
\hline & $600 \mathrm{~mm}$ & $85.22 \mathrm{MPa}$ & \\
\hline
\end{tabular}


Table 4. Sensitivity analysis of the computed HSS to the model parameters.

\begin{tabular}{cccc}
\hline Sensitivity analysis on computational parameters & HSS & Maximum variation \\
\hline Mesh size & $<1 \mathrm{~mm}$ & $82.19 \mathrm{MPa}$ & $5.5 \%$ \\
& $<2.5 \mathrm{~mm}$ & $82.69 \mathrm{MPa}$ & \\
& $<5 \mathrm{~mm}$ & $86.91 \mathrm{MPa}$ & \\
& $<12.5 \mathrm{~mm}$ & $87.59 \mathrm{MPa}$ & $5 \%$ \\
Element type & Linear 8-node & $84.96 \mathrm{MPa}$ & \\
& Quadratic 20 -node & $80.94 \mathrm{MPa}$ & $3 \%$ \\
Shell vs. solid & Shell & $81.38 \mathrm{MPa}$ & \\
& Solid & $84.09 \mathrm{MPa}$ & $7.7 \%$ \\
Integration method & Reduced & $84.96 \mathrm{MPa}$ & \\
& Full & $91.51 \mathrm{MPa}$ & $3.3 \%$ \\
Extrapolation method & Linear & $84.96 \mathrm{MPa}$ & \\
& Quadratic & $87.87 \mathrm{MPa}$ & \\
\end{tabular}

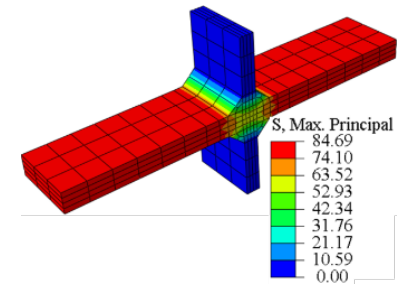

(a)

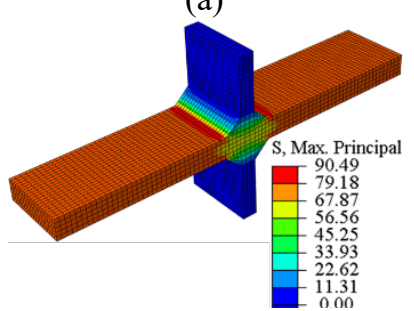

(c)

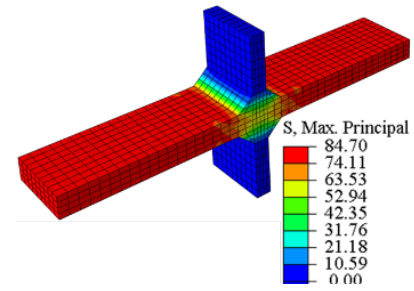

(b)

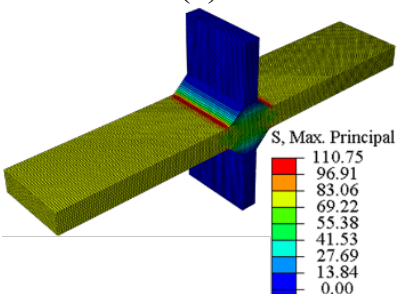

(d)

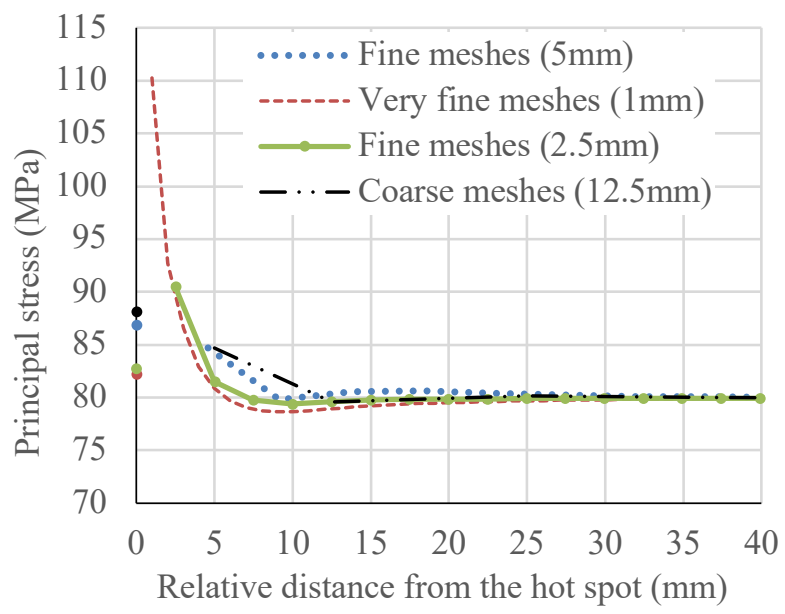

(e)

3 Fig. 13. Sensitivity of principal stress results to mesh size: (a) coarse mesh -12.5 by $12.5 \mathrm{~mm}$; (b) fine mesh -5 by $5 \mathrm{~mm}$;

(c) fine mesh -2.5 by $2.5 \mathrm{~mm}$; (d) very fine mesh -1 by $1 \mathrm{~mm}$.

\section{FATIGUE LIFE OF DUPLEX EN 1.4162 WELDED TRANSVERSE STIFFENER}

\subsection{Reference results collated in the literature} of data was done on similar welded details made of different material grades. In all these references, details were selected 
with a material nominal yield strength greater than $400 \mathrm{MPa}$. It is worth noting that the nominal yield strength of EN 1.4162 is $450 \mathrm{MPa}$ (for hot-rolled plates with $t<75 \mathrm{~mm}$ ) and many studies showed a positive influence of higher mechanical strengths on the fatigue resistance. A summary of the collated data is provided in Table 5 for stainless steel (SS), carbon steel (CS), high strength low alloy steel (HSLAS) and weathering steel (WS). It must be noted that all authors used the nominal stress method while building their S-N curves. The thickness of all the considered details is lower than $25 \mathrm{~mm}$ therefore, no size effect has been considered according to [8].

Table 5. Fatigue results for non-load-carrying transversal stiffeners.

\begin{tabular}{ccccc}
\hline Material grade & $\mathbf{R}$ & $\mathbf{n}$ & $\begin{array}{c}\text { S-N curve properties } \Delta \sigma_{c} \\
(\mathbf{9 5 \%} \text { fractile for } \mathbf{m}=\mathbf{3})\end{array}$ & Ref. \\
\hline SS EN 1.4462 & $0.1 / 0.5$ & 14 & 89 & {$[24]$} \\
SS EN 1.4462 & 0.1 & 17 & 88.2 & {$[27]$} \\
HSLAS A588 & $/$ & 68 & 88 & {$[75]$} \\
WS A572 & $/$ & 20 & 85 & {$[76]$} \\
HSLAS HT80 JIS & 0 & 11 & 90 & {$[77]$} \\
\hline
\end{tabular}

8

\subsection{Fatigue test}

In order to verify the predicted fatigue life according to the codified HSS method, four fatigue tests were carried out in the present research for a stress range corresponding to $110.4 \mathrm{MPa}$ with a stress ratio $\mathrm{R}=0.3$. During one of the tests, the HSS was continuously measured each $5 * 10^{5}$ cycle until a number of $2 * 10^{6}$ cycles was reached, after which the HSS was measured every $1.2 * 10^{6}$ cycles. This was done in order to assess how the HSS would vary during the sample's fatigue life. By doing so, one could examine the applicability of the method for determining the fatigue life of details in existing bridges that are in service. The test setup and the results of the measured HSS can be seen in Fig. 14. In all the fatigue tests, crack initiation, crack propagation and ultimate failure stages were observable, as highlighted in Fig. 14(d).

\subsection{Comparison and discussions}

The IIW guidelines give guidance to estimate the fatigue life through the use of so-called reference details. For transversal weld attachments, the reference detail is the FAT 100 type. Based on the measured or computed HSS, one can deduce the fatigue life following equations (6-7). In Fig. 15, one can see the S-N curves obtained through the HSS method (fatigue lives are based on experimentally measured or numerically computed HSS). In Fig. 16, the codified fatigue lives corresponding to the particular stress ranges according to the nominal stress method proposed in EN 1993 1-9, and the experimental fatigue 
1 lives collated in the literature as well as those presently obtained through four small-scale fatigue tests are provided. The

2 lower bounds in Fig. 15 and Fig. 16 correspond to a 95\% survival probability based on a linear regression analysis with a

3 fixed slope of $\mathrm{m}=3$. The linear regression analysis was performed following the IIW guideline as well as equations (8-10).

$4 \quad$ For $10000 \leq 5 * 10^{6}$;

$$
\begin{gathered}
N=\left(\frac{\Delta \sigma_{F A T}}{\sigma_{H S}}\right)^{m} * 2 * 10^{6} \Rightarrow m=3 \\
N=\left(\frac{\Delta \sigma_{D}}{\sigma_{H S}}\right)^{m} * 5 * 10^{6} \Rightarrow m=5
\end{gathered}
$$

where $\mathrm{N}$ is the number of cycles, $\sigma_{\mathrm{HS}}$ is experimental/computed HSS, $\Delta \sigma_{\mathrm{FAT}}$ is the reference detail category proposed in the IIW guideline which is $100 \mathrm{MPa}$ for transverse weld attachments, $\Delta \sigma_{\mathrm{D}}$ is the stress at the constant amplitude fatigue limit 8 (CAFL) of the same detail category which is $73.68 \mathrm{MPa}$ and $\mathrm{m}$ is the slope of the S-N curve.

$$
\begin{gathered}
\log N=\log C-m * \log \Delta \sigma \\
X_{k}=X_{m} \pm k \cdot S t d v \\
k=1.645 \cdot\left(1+\frac{1}{\sqrt{n}}\right)
\end{gathered}
$$

where $\mathrm{C}$ is a constant representing the influence of a structural detail, $\Delta \sigma$ is the applied stress range, $\mathrm{X}_{\mathrm{k}}$ is the characteristic value based on $\mathrm{X}_{\mathrm{m}}$ which is the mean of the values $\log \mathrm{C}, \mathrm{Stdv}$ is the standard deviation of the values of $\log \mathrm{C}$ and $\mathrm{k}$ is a factor depending on the number of considered samples $\mathrm{n}$ (see Table 6). The codes most commonly suggest mean values plus/minus two standard deviation which corresponds to a $95 \%$ survival probability with a $75 \%$ confidence interval.

Table 6. Values of $\mathrm{k}$ for the calculation of characteristic values.

\begin{tabular}{ccccccccc}
\hline $\mathbf{n}$ & $\mathbf{6}$ & $\mathbf{8}$ & $\mathbf{1 0}$ & $\mathbf{1 5}$ & $\mathbf{2 0}$ & $\mathbf{3 0}$ & $\mathbf{5 0}$ & $\mathbf{1 0 0}$ \\
\hline $\mathrm{k}$ & 2.32 & 2.23 & 2.17 & 2.07 & 2.01 & 1.95 & 1.88 & 1.81
\end{tabular}

The fatigue lives are plotted in logarithmic scale and one can notice that the characteristic fatigue strength obtained from the HSS method matches quite well with that obtained experimentally for similar details.

The codified HSS method yields results compatible with the actual fatigue tests collected from the literature for similar details. The estimated lower bound curve is slightly above the proposed detail category according to EC 1993 1-9. 


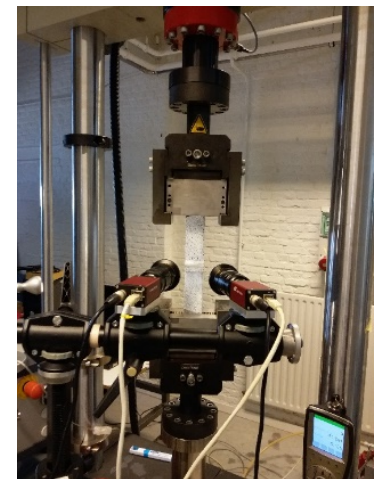

(a)

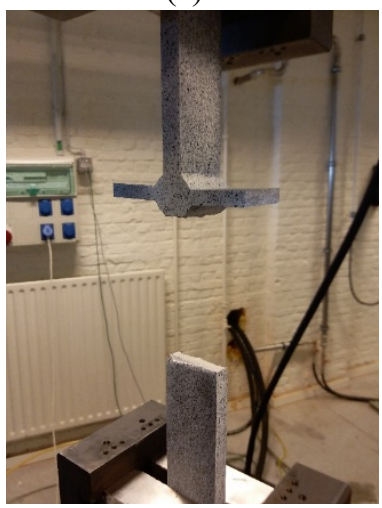

(c)
Maximum Principal Strain E1 []

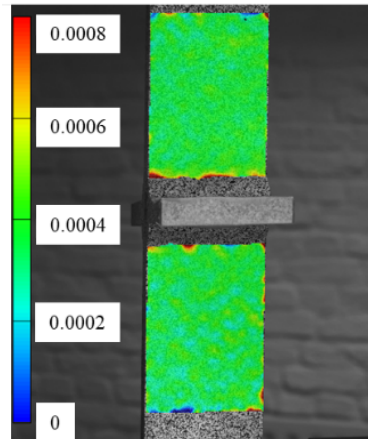

(b)

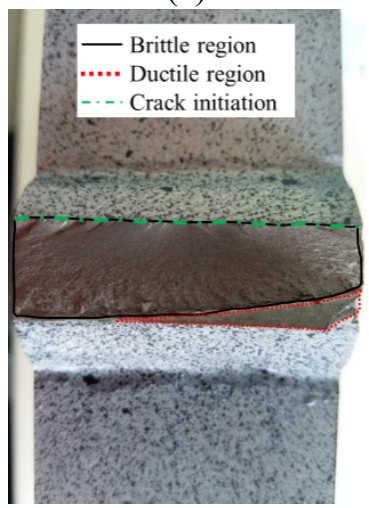

(d)

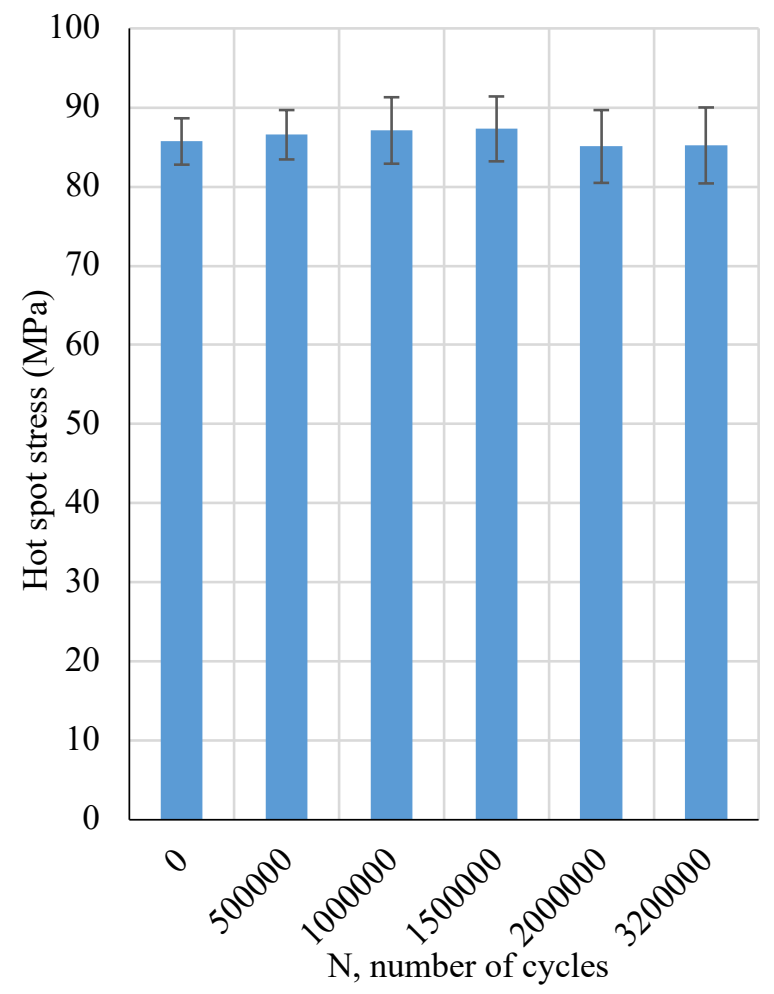

Fig. 14. Fatigue tests: (a) test setup with the cameras; (b) measured strain field at every 500000 cycles; (c) fatigue failure at the weld toe; (d) fracture surface; (e) evolution of hot spot stress during fatigue testing.

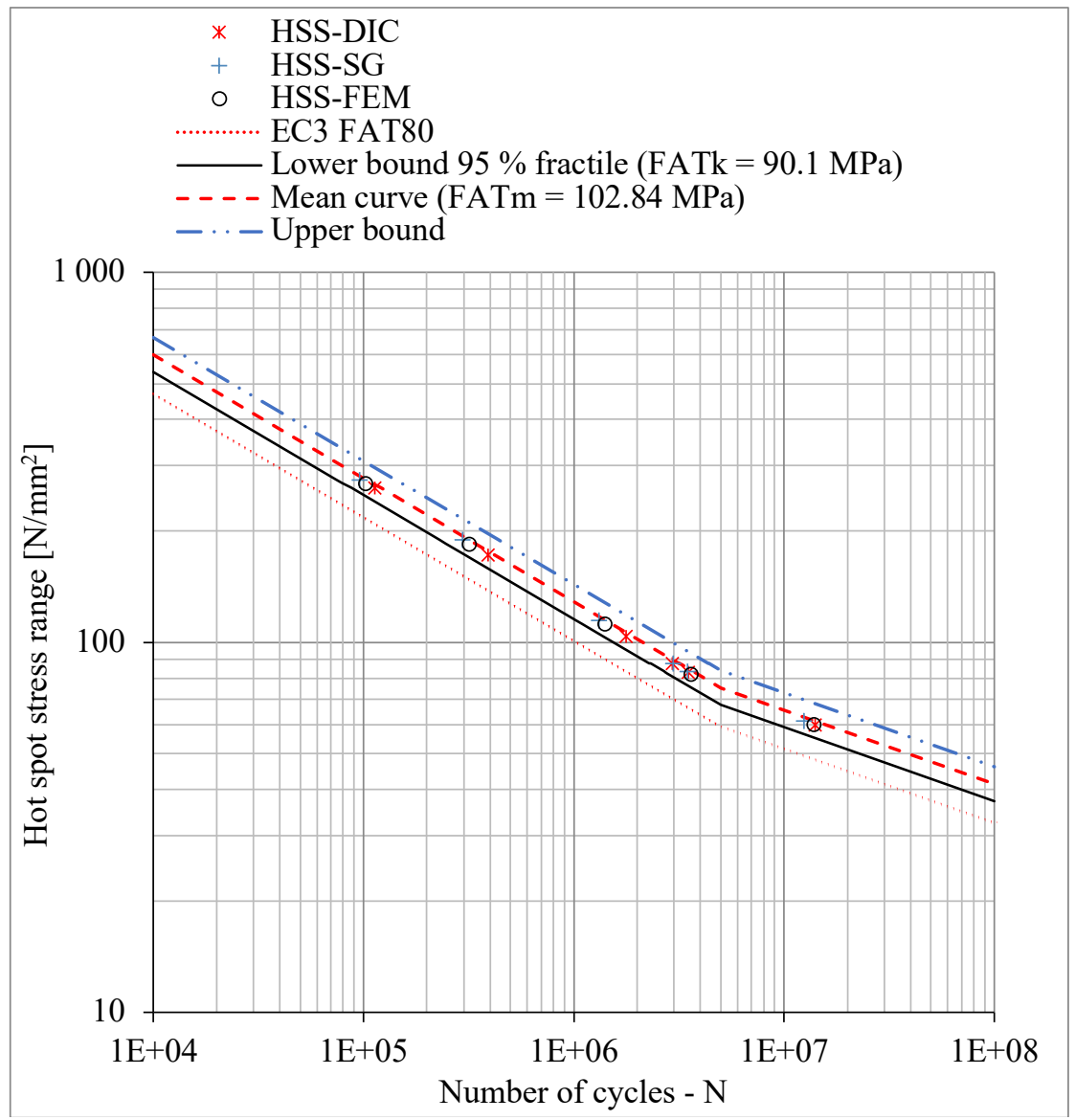

Fig. 15. Comparison of S-N curves for hot spot stress range (for $\mathrm{R}>0$ ). 


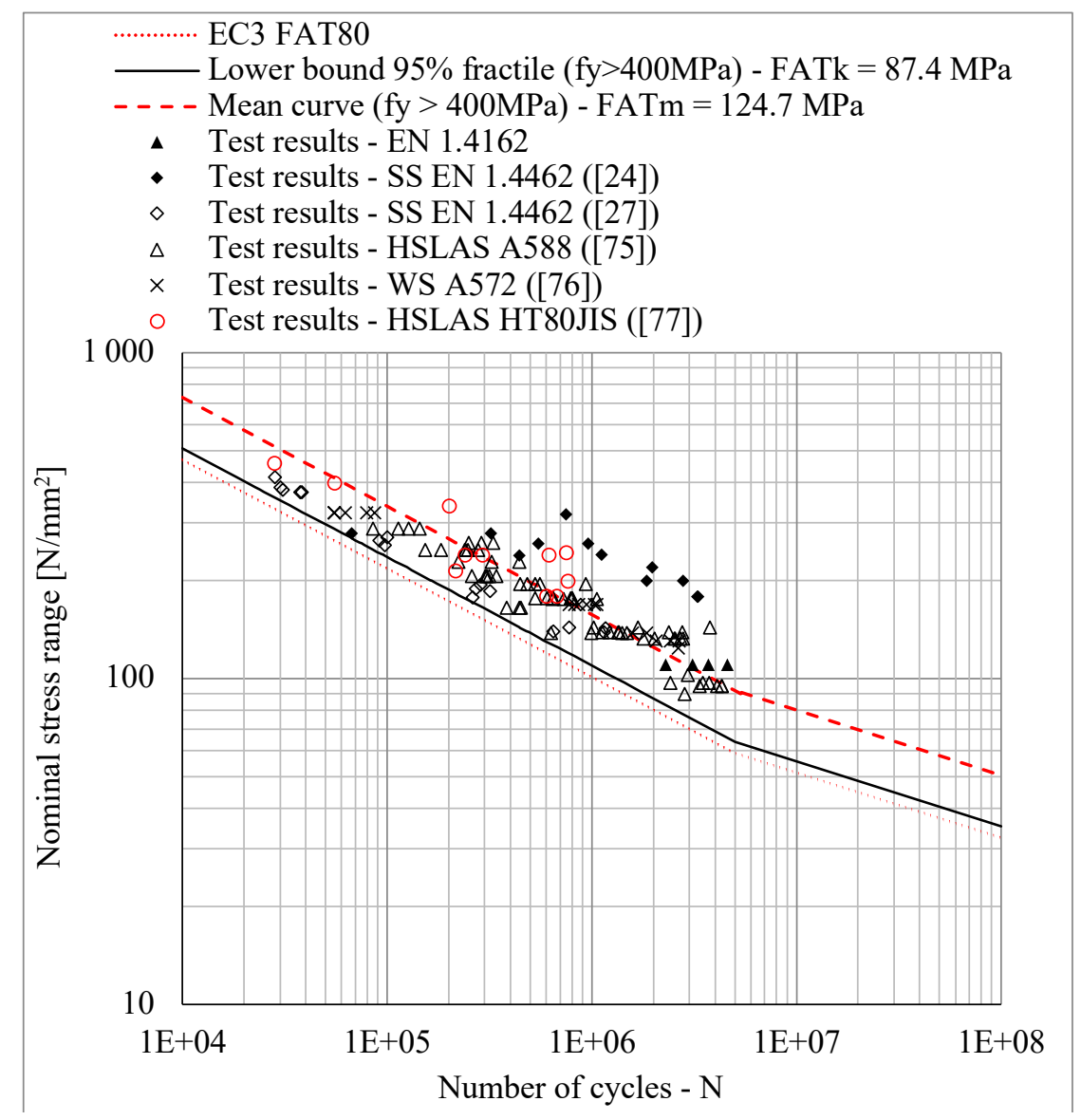

Fig. 16. Comparison of S-N curves for nominal stress range (for $\mathrm{R}>0$ ).

\section{CONCLUSIONS AND FUTURE WORKS}

In the present paper, welded duplex stainless steel stiffeners are studied. The hot spot stresses in non-load-carrying

4 cruciform welded joints are firstly measured through the use of two different techniques: digital image correlation (DIC) and, more traditionally, strain gauges. The stresses are then also computed through a finite element model. Following this, smallscale cyclic tests were carried out on the same detail and, a series of literature data on similar welded details, were collected.

7 The results are very consistent with each other and show the applicability of both the hot spot stress method and the nominal

8 stress approach. A comparison of the results leads to the following conclusions:

9 - Welding stainless steel requires specific attention when compared to mild steel. Keeping the heat input as low as possible and respecting the inter-pass temperature not to damage the balanced microstructure which plays a key role in corrosion resistance as well as mechanical properties are of paramount importance. These restrictions mainly result in a less wide heat affected zone compared to carbon steel components.

- DIC proved to be a robust measurement technique to evaluate the hot spot stress in welded components. The comparison with strain gauges is very consistent, with both methods resulting in very similar hot spot stresses and, therefore, predicted fatigue lives. 
- The results of the standardised hot spot stress method agree well with the fatigue test results. The method proved very effective in estimating the fatigue lives of the studied structural component.

- The Eurocode predictions remain slightly conservative, yet successfully evaluating the fatigue lives of the studied duplex welded detail.

- Fig. 14(e) provides the hot spot stress measurements on one duplex transversal stiffener during one of the fatigue test, indicating no change of the stress field during the test, also implying that the method could be safely used to assess already erected existing structures in service.

\section{ACKNOWLEDGEMENTS}

The first author is funded by the Impulsfonds for the PhD project "3E160992" at KU Leuven. We would like to gratefully acknowledge Outokumpu for providing samples of EN 1.4162 for this research.

\section{REFERENCES}

[1] Cui W. Review article A state-of-the-art review on fatigue life prediction methods for metal structures. J Mar Sci Technol 2002;7:43-56. doi: 10.1007/s007730200012

[2] Schütz W. A history of fatigue. Eng Fract Mech 1996;54:263-300. doi:10.1016/0013-7944(95)00178-6.

[3] Ye XW, Su YH, Han JP. A state-of-the-art review on fatigue life assessment of steel bridges. Math Probl Eng 2014;2014:1-13. doi:10.1155/2014/956473.

[4] Reed RP, Smith JH, Christ BW. The economic effects of fracture in the united states part $1-$ a synopsis of September 30, 1982 report to NBS by Battelle Columbus Laboratories. National Bureau of Standards Special Publication 647-1; Washington, USA; 1983.

[5] Duga JJ, Fisher WH, Buxbaum RW, Rosenfield AR, Buhr AR, Honton EJ, McMillan SC. The economic effects of fracture in the United States part 2 - A report to NBS by Battelle Columbus Laboratories. National Bureau of Standards Special Publication 647-2; Washington, USA; 1983.

[6] ASCE Committee on Fatigue and Fracture Reliability. Fatigue reliability: introduction. Journal of the Structural Division 1982;108:3-23.

[7] Nussbaumer A, Borges L, Laurence D. Fatigue design of steel and composite structures, 1st ed. ECCS - European Convention for Constructional Steelwork; 2011.

[8] European Committee for Standardization (CEN), EN 1993-1-9. Eurocode3. Design of steel structures - part 1-9: Fatigue. European Standard; 2005 
[9] European Committee for Standardization (CEN), EN 1993-1-10. Eurocode3. Design of steel structures - part 1-10: Material toughness and through-thickness properties. European Standard; 2005

[10] Hobbacher A. Recommendations for fatigue design of welded joints and components, 2 nd ed. The International Institute of Welding, IIW-2259-15, ex XIII-2460-13/XV-1440-13; Springer International Publishing; 2016. doi:10.1007/978-3-319-23757-2.

[11] Aygül M, Bokesjö M, Heshmati M, Al-Emrani M. A comparative study of different fatigue failure assessments of welded bridge details. Int J Fatigue 2013;49:62-72. doi:10.1016/j.ijfatigue.2012.12.010.

[12] Al-Emrani M, Kliger R. Fatigue prone details in steel bridges. In: Nordic Steel Construction Conference; Malmö, Sweden; 2009.

[13] Haghani, R., Al-Emrani, M., Heshmati. Fatigue-prone details in steel bridges. Buildings 2012;2012:456-476. doi:10.3390/buildings2040456.

[14] Lukic M, Kühn B. Fatigue and fracture from assessment to best practice a collection of historical damage cases in

[15] Baddoo NR. Stainless steel in construction: A review of research, applications, challenges and opportunities. J

[16] Berezovskaya V V., Kostina M V., Blinov E V., Bannykh IO, Bobrova VE, Mel'nik VP. Corrosion properties of doi:10.1134/S0036029508010060.

[17] Euro Inox/SCI. Design manual for structural stainless steel. 4th ed. Euro Inox and the Steel Construction Institute; 2017.

[18] Merello R, Botana FJ, Botella J, Matres MV, Marcos M. Influence of chemical composition on the pitting corrosion resistance of non-standard low-Ni high-Mn-N duplex stainless steels. Corros Sci 2003;45:909-21. doi:10.1016/S0010938X(02)00154-3.

[19] Iversen AK. Stainless steels in bipolar plates-Surface resistive properties of corrosion resistant steel grades during current loads. Corros Sci 2006;48:1036-58. doi:10.1016/j.corsci.2005.05.012.

[20] Olsson J, Snis M. Duplex - A new generation of stainless steels for desalination plants. Desalination 2007;205:104 13. doi:10.1016/j.desal.2006.02.051.

[21] Wei Z, Laizhu J, Jincheng H, Hongmei S. Study of mechanical and corrosion properties of a Fe-21.4Cr-6Mn-1.5Ni0.24N-0.6Mo duplex stainless steel. Mater Sci Eng A 2008;497:501-4. doi:10.1016/j.msea.2008.07.062. 
[22] Baddoo NR, Kosmac A. Sustainable duplex stainless steel bridges. In: 8th Duplex Stainless Steels Conference; Steel Construction Institute (SCI); Ascot, UK; 2010.

[23] European Committee for Standardization (CEN), EN 1993-1-4. Eurocode3. Design of steel structures - part 1-4: General rules - Supplementary rules for stainless steels. European Standard; 2012

[24] Branco CM, Maddox SJ, Sonsino CM. Fatigue design of welded stainless steels. The European Coal and Steel Community (ECSC); Brussels, Belgium; 2001.

[25] Liljas M., Ericsson C. Fatigue behaviour of stainless steel welds. In: AvestaPolarit Corrosion Management and Application Engineering; Avesta, Sweden; 2002.

[26] Ericsson C, Johansson P, Liljas M, Westin EM. Mechanical properties of welds in the new lean duplex stainless steel LDX 2101® (EN 1.4162, UNS S32101). In: Stainless Steel World; The Hague, The Netherlands; 2003.

[27] Zilli G, Maiorana E, Peultier J, Fanica A, Hechler O, Rauert T, Maquoi R. Application of duplex stainless steel for welded bridge construction in an aggressive environment. Research Fund for Coal and Steel (RFCS); Brussels, Belgium; 2008.

[28] Al-Rubaie KS. A general model for stress-life fatigue prediction. Materwiss Werksttech 2008;39:400-6. doi:10.1002/mawe.200800282.

[29] Basquin OH. The exponential law of endurance tests. Proc Am Soc Test Mater 1910;10:625-30.

[30] Stromeyer CE. The determination of fatigue limits under alternating stress conditions. In: Proceedings of the Royal Society. vol. 90. 1914. p. 411-425.

[31] Walker EK. The effect of stress ratio during crack propagation and fatigue for 2024-T3 and 7075-T6 aluminium. In: Effects of Environment and Complex Load History on Fatigue Life; ASTM Special Technical Publication; American Society for Testing and Materials, Philadelphia, USA. vol. 462. 1970. p. 1-14.

[32] Xiao ZG, Yamada K. A method of determining geometric stress for fatigue strength evaluation of steel welded joints. Int J Fatigue 2004;26:1277-93. doi:10.1016/j.ijfatigue.2004.05.001.

[33] Poutiainen I, Tanskanen P, Marquis G. Finite element methods for structural hot spot stress determination - A comparison of procedures. Int J Fatigue 2004;26:1147-57. doi:10.1016/j.ijfatigue.2004.04.003.

[34] Aygül M, Al-Emrani M, Urushadze S. Modelling and fatigue life assessment of orthotropic bridge deck details using FEM. Int J Fatigue 2012;40:129-42. doi:10.1016/j.ijfatigue.2011.12.015.

[35] Radaj D, Sonsino CM, Fricke W. Fatigue assessment of welded joints by local approaches, 2nd edition. Abington publishing; Cambridge, UK; 2006. 
[36] Radaj D. Review of fatigue strength assessment of nonwelded and welded structures based on local parameters. Int J Fatigue 1996;18:153-70. doi:10.1016/0142-1123(95)00117-4.

[37] Morgan MR, Lee MMK. New parametric equations for stress concentration factors in tubular K-joints under balanced axial loading. Int J Fatigue 1997;19:309-17. doi:10.1016/S0142-1123(96)00081-3.

[38] Park JY, Kim H-K. Fatigue life assessment for a composite box girder bridge. Int J Steel Struct 2014;14:843-53. doi:10.1007/s13296-014-1215-x.

[39] Liu R, Liu Y, Ji B, Wang M, Tian Y. Hot spot stress analysis on rib-deck welded joint in orthotropic steel decks. J Constr Steel Res 2014;97:1-9. doi:10.1016/j.jcsr.2014.01.012.

[40] Lee J-M, Seo J-K, Kim M-H, Shin S-B, Han M-S, Park J-S. Comparison of hot spot stress evaluation methods for welded structures. Int J Nav Archit Ocean Eng 2010;2:200-10. doi:10.2478/IJNAOE-2013-0037.

[41] Fricke W, Gao L, Paetzold H. Fatigue assessment of local stresses at fillet welds around plate corners. Int J Fatigue 2017;101:169-76. doi:10.1016/j.ijfatigue.2017.01.011.

[42] Ji B, Liu R, Chen C, Maeno H, Chen X. Evaluation on root-deck fatigue of orthotropic steel bridge deck. J Constr Steel Res 2013;90:174-83. doi:10.1016/j.jcsr.2013.07.036.

[43] Fung TC, Soh CK, Chan TK, Erni. Stress concentration factors of doubler plate reinforced tubular T joints. J Struct Eng 2002;128:1399-412. doi:10.1061/(asce)0733-9445(2002)128:11(1399).

[44] Puthli RS, Wardenier J, De Koning CHM, Van Wingerde AM, Van Dooren FJ. Numerical and experimental determination of strain (stress) concentration factors of welded joints between square hollow sections. Heron. vol. 33, no. 2; Delft, The Netherlands; 1988.

[45] Gao F, Shao YB, Gho WM. Stress and strain concentration factors of completely overlapped tubular joints under lap brace IPB load. J Constr Steel Res 2007;63:305-16. doi:10.1016/j.jcsr.2006.05.007.

[46] Gho WM, Fung TC, Soh CK. Stress and strain concentration factors of completely overlapped tubular K(N) joints. J Struct Eng 2002;129:21-9. doi:10.1061/(asce)0733-9445(2003)129:1(21).

[47] Karamanos, Spyros B, Member A, Romeijn A, Wardenier J. Stress concentrations in tubular DT-joints for fatigue design. J Struct Eng 2000;126:1320-30.

[48] Van Wingerde AM, Packer JA, Wardenier J. Criteria for the fatigue assessment of hollow structural section connections. J Constr Steel Res 1995;35:71-115. doi:10.1016/0143-974X(94)00030-I.

[49] Yagi J, Machida S, Tomita Y, Matoba M, Kawasaki T. Definition of hot spot stress in welded plate type structure for fatigue assessment. The International Institute of Welding, IIW Document XIII-1414-91;Villeurbanne, France; 1991. 
[50] Dong P. A structural stress definition and numerical implementation for fatigue analysis of welded joints. Int J Fatigue 2001;23:865-76. doi:10.1016/S0142-1123(01)00055-X.

3 [51] Miki C, Tateishi K. Fatigue strength of cope hole details in steel bridges. Int J Fatigue 1997;19:445-55. doi:10.1016/S0142-1123(97)85727-1.

[52] Savaidis G, Vormwald M. Hot-spot stress evaluation of fatigue in welded structural connections supported by finite element analysis. Int J Fatigue 2000;22:85-91. doi:10.1016/S0142-1123(99)00119-X.

[53] Han S, Shin B. Use of hot spot stress for estimating the fatigue strength of welded components. Steel Res 2000;71:466-73. doi:10.1002/srin.200005716.

[54] Chan THT, Guo L, Li ZX. Finite element modelling for fatigue stress analysis of large suspension bridges. J Sound Vib 2003;261:443-64. doi:10.1016/S0022-460X(02)01086-6.

[55] Doerk O, Fricke W, Weissenborn C. Comparison of different calculation methods for structural stresses at welded joints. Int J Fatigue 2003;25:359-69. doi:10.1016/S0142-1123(02)00167-6.

[56] Chan THT, Zhou TQ, Li ZX, Guo L. Hot spot stress approach for Tsing Ma Bridge fatigue evaluation under traffic using finite element method. Struct Eng Mech 2005;19:261-79. doi:10.12989/sem.2005.19.3.261.

[57] DNV-RP-203 fatigue design of offshore steel structures, Det Norske Veritas-Offshore Codes, Norway; 2010.

[58] European Committee for Standardization (CEN), EN 1999-1-3. Eurocode9. Design of aluminium structures - part 1-3: Structures susceptible to fatigue. European Standard; 2007

[59] Niemi E. Stress determination for fatigue analysis of welded components. The International Institute of Welding,

[60] Niemi E, Fricke W, Maddox SJ. Fatigue analysis of welded components: Designer's guide to the structural hot-spot

[63] Schreier H, Orteu JJ, Sutton MA. Image correlation for shape, motion and deformation measurements. Springer; 2009. doi: 10.1007/978-0-387-78747-3 
[64] Al-Emrani M. Fatigue performance of stringer-to-floor-beam connections in riveted railway bridges. J Bridg Eng 2005;10:179-85. doi:10.1061/(asce)1084-0702(2005)10:2(179).

3 [65] Fortan M., De Wilder K., Debruyne D., Rossi B. Shear buckling of lean duplex stainless steel plate girders with nonrigid end posts. In: Proceedings of the 8th International Conference on Steel and Aluminium Structures (ICSAS 2016); Hong Kong, China; 2016. p. 1-18. ISBN: 978-962-8014-26-2.

[66] Karabulut B., Lombaert G., Debruyne D., Rossi B. Numerical investigations on the fatigue life of lean duplex transverse stiffeners in bridges. In: 18th International Conference on Experimental Mechanics (ICEM 2018); Brussels, Belgium; 2018. doi: 10.3390/ICEM18-05278.

[67] Kramer SLB, Scherzinger WM. Implementation and evaluation of the virtual fields method: Determining constitutive model parameters from full-field deformation data. Sandia National Laboratories; 2014.

[69] Fernández, JAP; Coppieters, S; Debruyne, D. 2016. Application of digital image correlation for the study of strain

[68] Grediac M, Pierront F, Avrilt S, Toussaint E. Constitutive parameters from full-field. Strain 2006;42:233-53. concentrations due to change in geometry in weld beads: parent interface of structural steel welds. Science and Technology of Welding and Joining; 2016;21:670-79. doi:10.1080/13621718.2016.1174359.

[70] Kotecki, D.J. Some pitfalls in welding of duplex stainless steels. Soldagem and Inspeção 2010;15:336-343. doi:10.1590/S0104-92242010000400011.

[71] EN ISO 5817. Welding — Fusion-welded joints in steel, nickel, titanium and their alloys (beam welding excluded) — Quality levels for imperfections; 2014. https:/www.iso.org/standard/54952.html

[72] ASTM E562-19, Standard Test Method for Determining Volume Fraction by Systematic Manual Point Count; ASTM International, West Conshohocken, PA; 2019. doi: 10.1520/E0562-19

[73] Karlsson L. Welding duplex stainless steels: A review of current recommendations. Zavar i Zavarene Konstr 2018;63:29-35. doi:10.5937/zzk1801029k.

[74] EN ISO 6892-1. Metallic materials — Tensile testing — Part 1: Method of test at room temperature; 2016. https://www.iso.org/standard/61856.html

[75] Albrecht P., Friedland IM. Fatigue-limit effect on variable-amplitude fatigue of stiffeners. Journal of the Structural Division 1979;105:2657-75.

[76] Klippstein KH, Schilling CG. Pilot study on the constant and variable amplitude behavior of transverse stiffener welds. J Constr Steel Res 1989;12:229-52. doi:10.1016/0143-974X(89)90057-6.

[77] Tajima J, Okukawa A., Tanaka Y. Fatigue design criteria on Honshu-Shikoku suspension bridges. IABSE congress report; 1976. doi: 10.5169/seals-10467 
1 [78] Karabulut B, Lombaert G, Debruyne D, Rossi B. Optimized design and life cycle cost analysis of a duplex welded girder bridge. In Proceedings of the International Symposium On Life-Cycle Civil Engineering, Ghent, Belgium, 2018.

3 [79] Pedro JO, Reis A, Baptista C. High strength steel (HSS) S690 in highway bridges: Comparative design. In:

4 Proceedings of the Eurosteel, Copenhagen, Denmark; 2017. doi: 10.1002/cepa.462

5 [80] Guilherme A, De Jesus A, Da Silva JGS, Galçada R. Fatigue cracking of welded railway bridges: A review. Eng Fail Anal 2019;104:154-76. doi:10.1016/j.engfailanal.2019.05.037 